\title{
Antiplatelet Activity of Morus alba Leaves Extract, Mediated via Inhibiting Granule Secretion and Blocking the Phosphorylation of Extracellular-Signal-Regulated Kinase and Akt
}

\author{
Dong-Seon Kim, ${ }^{1}$ Hyun Dong Ji, ${ }^{2}$ Man Hee Rhee, ${ }^{2}$ Yoon-Young Sung, ${ }^{1}$ Won-Kyung Yang, \\ Seung Hyung Kim, ${ }^{3}$ and Ho-Kyoung Kim ${ }^{1}$ \\ ${ }^{1}$ Basic Herbal Medicine Research Group, Korea Institute of Oriental Medicine, Daejeon 305-811, Republic of Korea \\ ${ }^{2}$ College of Veterinary Medicine, Kyungpook National University, Daegu 702-701, Republic of Korea \\ ${ }^{3}$ Institute of Traditional Medicine \& Bioscience, Daejeon University, Daejeon 300-716, Republic of Korea
}

Correspondence should be addressed to Ho-Kyoung Kim; hkkim@kiom.re.kr

Received 23 September 2013; Revised 21 December 2013; Accepted 30 December 2013; Published 19 February 2014

Academic Editor: Joen-Rong Sheu

Copyright (c) 2014 Dong-Seon Kim et al. This is an open access article distributed under the Creative Commons Attribution License, which permits unrestricted use, distribution, and reproduction in any medium, provided the original work is properly cited.

\begin{abstract}
Ethnopharmacological Relevance. Morus alba L. leaves (MAE) have been used in fork medicine for the treatment of beriberi, edema, diabetes, hypertension, and atherosclerosis. However, underlying mechanism of MAE on cardiovascular protection remains to be elucidated. Therefore, we investigated whether MAE affect platelet aggregation and thrombosis. Materials and Methods. The anti-platelet activity of MAE was studied using rat platelets. The extent of anti-platelet activity of MAE was assayed in collageninduced platelet aggregation. ATP and serotonin release was carried out. The activation of integrin $\alpha_{\text {IIb }} \beta_{3}$ and phosphorylation of signaling molecules, including MAPK and Akt, were investigated with cytofluorometer and immunoblotting, respectively. The thrombus formation in vivo was also evaluated in arteriovenous shunt model of rats. Results. HPLC chromatographic analysis revealed that MAE contained rutin and isoquercetin. MAE dose-dependently inhibited collagen-induced platelet aggregation. MAE also attenuated serotonin secretion and thromboxane $\mathrm{A}_{2}$ formation. In addition, the extract in vivo activity showed that MAE at 100 , 200 , and $400 \mathrm{mg} / \mathrm{kg}$ significantly and dose-dependently attenuated thrombus formation in rat arterio-venous shunt model by $52.3 \%$ $(P<0.001), 28.3 \%(P<0.01)$, and 19.1\% $(P<0.05)$, respectively. Conclusions. MAE inhibit platelet activation, TXB2 formation, serotonin secretion, aggregation, and thrombus formation. The plant extract could be considered as a candidate to anti-platelet and antithrombotic agent.
\end{abstract}

\section{Introduction}

Cardiovascular diseases, including thrombosis, stroke, ischemic, and coronary heart diseases, are a leading cause of mortality, accounting for around 30\% of global deaths [1]. Especially, thrombotic diseases constitute a major cardiovascular complication affecting a great number of patients. Thrombosis is closely related to activated platelet adhesion, aggregation, secretion functions, and activation of intrinsic and extrinsic coagulation systems, which cause blood coagulation and fibrin formation [2]. Most acute coronary syndromes are caused by platelet aggregation and subsequent thrombus formation in areas of ruptured atheromatous plaques $[3,4]$. Therefore, inhibiting platelet function represents a promising approach for preventing thrombosis $[5,6]$.

Antiplatelet drugs have been developed to inhibit platelet activity in acute thrombotic situations as well as to prevent adverse events and treatment of atherothrombotic disease [7]. Aspirin and clopidogrel for oral administration and glycoprotein IIa/IIIb antagonists (abciximab, eptifibatide, tirofiban, etc.) for injection are commonly used antiplatelet drugs, but they have several clinical disadvantages including gastrointestinal side-effects, hemorrhage and thrombocytopenia [711]. With this regards, much attention has been given to the 
development of dietary supplements or herbal medicines for prevention or treatment of cardiovascular diseases for their merits in safety [12].

Morus alba L. (Mulberry) leaf belongs to the Moraceae family, distributed mainly in the temperate and subtropical regions in the northern hemisphere. It has been traditionally used in China, Korea, Japan, and other Asian countries as herbal tea as well as herbal medicine. According to the oldest Korean medical book (Dong-ui-bo-gam), it is called "SangYeop" and introduced to be beneficial in alleviating beriberi, edema and pains [13].

Recent studies have reported that it shows antiatherosclerosis [14], antihypertension [15, 16], antiobesity [17], antidiabetic $[18,19]$, liver protection [20], antiviral [21] and antimicrobial [22] effects. This antiplatelet or antithrombotic effect of $M$. alba leaves has never been described before, though an antiplatelet effect has been described with its barks [23].

In this study, we discovered that the $M$. alba leaves extract has strong inhibitory activities on collagen-induced platelet aggregation in vitro and on thrombosis in vivo.

\section{Materials and Methods}

2.1. Materials. Collagen was obtained from Chrono-Log Co. (Havertown, PA, USA). Aspirin, fibrinogen, plasmin and dimethyl sulfoxide (DMSO) were from Sigma Chemical Co. (St. Louis, MO, USA). Fura-2/AM was obtained from Sigma Chemical Co. (St. Louis, MO, USA). Antibodies against phospho-p44/42, p44/42, phospho-p38, p38, phospho-SAPK/JNK, phospho-PI3K (p85), phospho-Akt, and $\beta$-actin were acquired from Cell Signaling (Beverly, MA, USA). ATP assay kits were purchased from Biomedical Research Service Center (Buffalo, NY, USA). A TXB 2 enzyme immunoassay (EIA) kit was from Cayman Chemical (Ann Arbor, MI, USA). Fibrinogen Alexa Fluor 488 conjugate was obtained from Molecular Probes (Eugene, OR, USA). HPLCgrade reagents, methanol and water were obtained from J. T. Baker (Phillipsburg, NJ, USA). All other chemicals were of reagent grade.

2.2. Preparation of the Ethanol Extract and Solvent Fractions from Morus alba. Morus alba leaves as a dried herb was purchased from Omniherb Co. (Yeongcheon, Korea) and was authenticated, based on its microscopic and macroscopic characteristics, by the Classification and Identification Committee of the Korea Institute of Oriental Medicine (KIOM). The committee consisted of nine experts in the fields of plant taxonomy, botany, pharmacognosy, and herbology. A voucher specimen (MAL-20120605) was deposited at the herbarium of the Department of Herbal Resources Research at the KIOM.

Dried leaves of Morus alba (500 g) were extracted twice with $70 \%(\mathrm{v} / \mathrm{v})$ ethanol $(5 \mathrm{~L})$ for $4 \mathrm{~h}$ under mantle-reflux. The extracts were filtered and evaporated under reduced pressure to give Morus alba leaves extract (MAE, 56.0 g). The extract ( $40 \mathrm{~g}$ ) was suspended in water $(1.2 \mathrm{~L})$ to be partitioned subsequently with $n$-hexane $(2 \times 1.2 \mathrm{~L})$, ethyl acetate $(2 \times$ $1.2 \mathrm{~L})$, and then $n$-butanol $(2 \times 1.2 \mathrm{~L})$ and the solvent-soluble fractions were evaporated to afford hexane- $(3.9 \mathrm{~g})$, ethyl acetate- (1.8 g), butanol- (6.7 g) and water-soluble (27.6 g) fraction, respectively.

The extract and the fractions were dissolved in saline or phosphate-buffered saline (PBS) and then filtered through a $0.22 \mathrm{~m}$ syringe filter for experiments.

2.3. High Performance Liquid Chromatography Analysis. The sample was analyzed by reverse phase-high performance liquid chromatography using Waters Alliance 2695 system (Waters Co., Milford, MA, USA), coupled with a 2996 photodiode array detector. Data processing was carried out using Empower software (Waters Co.). Phenomenex Luna C18 column ( $250 \mathrm{~mm} \times 4.6 \mathrm{~mm}$; particle size $5 \mu \mathrm{m}$, Phenomenex, Torrance, CA, USA) was used as stationary phase. The mobile phase consisted of eluent A ( $0.1 \%$ trifluoroacetic in water) and eluent B (acetonitrile). The starting eluent was 90\% A and $10 \% \mathrm{~B}$. The proportion of eluent B was increased linearly to $40 \%$ from $10 \mathrm{~min}$ to $40 \mathrm{~min}$. The column temperature was kept at $40^{\circ} \mathrm{C}$ and the detector wavelength was set over the range of 190 to $400 \mathrm{~nm}$ and recorded at $360 \mathrm{~nm}$. The flow rate was $1.0 \mathrm{~mL} / \mathrm{min}$, and the injection volume was $10 \mu \mathrm{L}$, and the column temperature was kept at $40^{\circ} \mathrm{C}$.

Identification was based on retention time, UV spectra by comparison with commercial standards. For each compound, peak areas were determined at the wavelength providing maximal UV absorbance. Calibration curves of the standards ranging from 12.5 to $200 \mu \mathrm{g} / \mathrm{mL}$ (5 levels) revealed good linearity with $R^{2}$ values exceeding 0.99 (peak areas versus concentration). Quantitation was performed based on external standards with a mixture of standards of known concentration that were analyzed in duplicate before and after the batch of samples, and the peak areas were used to calculate the sample contents of the compounds.

2.4. Experimental Animals. Male Sprague Dawley rats (300 $350 \mathrm{~g}$ ) were purchased from Japan SLC (Hamamatsu, Japan). The animals were acclimated for 1 week prior to the experiments, and housed in an air-conditioned animal room with a 12/12 h light/dark cycle at a temperature of $22 \pm 1^{\circ} \mathrm{C}$ and humidity of $50 \pm 10 \%$. The animals were provided with a laboratory diet and water ad libitum.

All experimental protocols involving the use of animals were conducted in accordance with National Institutes of Health (NIH) guidelines and approved by the Committee on Animal Care at the Korea Institute of Oriental Medicine.

2.5. Washed Rat Platelet Preparation. Blood was withdrawn from abdominal vein of rats and collected directly into anticoagulant citrate dextrose (ACD) solution that contained $0.8 \%$ citric acid, $2.2 \%$ trisodium citrate, and $2 \%$ dextrose $(\mathrm{w} / \mathrm{v})$. Washed platelets were prepared as previously described [24]. Briefly, platelet-rich plasma (PRP) was obtained by centrifuging rabbit blood samples at $230 \times \mathrm{g}$ for $10 \mathrm{~min}$. Platelets were precipitated by centrifugation of the PRP at $800 \times \mathrm{g}$ for $15 \mathrm{~min}$ and washed with HEPES buffer (137 mM NaCl, $2.7 \mathrm{mM} \mathrm{KCl,} 1 \mathrm{mM} \mathrm{MgCl}_{2}, 5.6 \mathrm{mM}$ glucose, $3.8 \mathrm{mM}$ HEPES, and $\mathrm{pH}$ 6.5) containing $0.35 \%$ BSA and $0.4 \mathrm{mM}$ EGTA. The washed platelets were resuspended in 
HEPES buffer ( $\mathrm{pH} 7.4$ ) and the cell dilution was adjusted to 4 $\times 10^{8}$ cells $/ \mathrm{mL}$.

2.6. Platelet Aggregation In Vitro Assay. Platelet aggregation was evaluated as previously described [25]. Aggregation was monitored by measuring light transmission with an aggregometer (Chrono-Log, Havertown, PA, USA). The washed platelets $\left(3 \times 10^{8} / \mathrm{mL}\right)$ were pre-incubated at $37^{\circ} \mathrm{C}$ for 2 min with either MAE or vehicle and then stimulated with $2.5 \mu \mathrm{g} / \mathrm{mL}$ collagen. The mixture was further incubated for 5 min with stirring at $170 \times \mathrm{g}$. The vehicle concentration was less than $0.1 \%$ to minimize the effect of this reagent.

2.7. $\left[\mathrm{Ca}^{2+}\right]_{i}$ Measurement. The intracellular calcium ion concentration $\left(\left[\mathrm{Ca}^{2+}\right]_{i}\right)$ was measured with Fura-2/AM as previously described [26]. Briefly, the platelets were incubated with $5 \mu \mathrm{M}$ of Fura-2/AM for $30 \mathrm{~min}$ at $37^{\circ} \mathrm{C}$ and washed. The Fura2-loaded platelets $\left(3 \times 10^{8} / \mathrm{mL}\right)$ were then pre-incubated with $\mathrm{MAE}$ for $2 \mathrm{~min}$ at $37^{\circ} \mathrm{C}$ in the presence of $1 \mathrm{mM} \mathrm{CaCl}$ and subsequently stimulated with collagen for $5 \mathrm{~min}$. Fluorescent signals were recorded using a Hitachi F-2500 fluorescence spectrofluorometer (F-2500, Hitachi, Japan). Light emission was measured at $510 \mathrm{~nm}$ with simultaneous excitation at 340 and $380 \mathrm{~nm}$ that changed every $0.5 \mathrm{~s}$. Fura-2 fluorescence in the cytosol measured with the spectrofluorometer was calculated as previously described by Schaeffer and Blaustein [27] with the following formula: $\left[\mathrm{Ca}^{2+}\right]_{i} 224 \mathrm{nM} \times(F-$ $\left.F_{\min }\right) /\left(F_{\max }-F\right)$, in which $224 \mathrm{nM}$ is the dissociation constant of the Fura-2-Ca ${ }^{2+}$ complex, and $F_{\min }$ and $F_{\max }$ represent the fluorescence intensity levels at very low and very high $\mathrm{Ca}^{2+}$ concentrations, respectively. In our experiment, $F_{\max }$ was the intensity of the Fura-2-Ca ${ }^{2+}$ complex fluorescence at $510 \mathrm{~nm}$ after the platelet suspension containing $1 \mathrm{mM}$ of $\mathrm{CaCl}_{2}$ had been solubilized with Triton X-100 (0.1\%). $F_{\min }$ was the fluorescence intensity of the Fura-2- $\mathrm{Ca}^{2+}$ complex at $510 \mathrm{~nm}$ after the platelet suspension containing $20 \mathrm{mM}$ Tris $/ 3 \mathrm{mM}$ of EGTA had been solubilized with Triton X-100 (0.1\%). $F$ represented the intensity of Fura- 2 complex fluorescence at $510 \mathrm{~nm}$ after the platelet suspension was stimulated with collagen with or without MAE in the presence of $1 \mathrm{mM} \mathrm{CaCl}_{2}$.

2.8. ATP Release Assay. Washed platelets $\left(3 \times 10^{8} / \mathrm{mL}\right)$ were pre-incubated for $2 \mathrm{~min}$ at $37^{\circ} \mathrm{C}$ with various concentrations of MAE and then stimulated with $2.5 \mu \mathrm{g} / \mathrm{mL}$ collagen. After the reaction was terminated, the cells were centrifuged and the supernatants were used for the assay. ATP release was measured in a luminometer (GloMax 20/20; Promega, Madison, USA) using an ATP assay kit (Biomedical Research Service Center, Buffalo, NY, USA) according to manufacturer's instructions.

2.9. Measurement of Serotonin Secretion. The washed platelets $\left(3 \times 10^{8} / \mathrm{mL}\right)$ were pre-incubated for $2 \mathrm{~min}$ at $37^{\circ} \mathrm{C}$ with various concentrations of MAE in the presence of $1 \mathrm{mM}$ of $\mathrm{Ca}^{2+}$. The reaction mixture was further incubated with collagen $(2.5 \mu \mathrm{g} / \mathrm{mL})$ for $5 \mathrm{~min}$. After terminating the aggregation reaction, the mixture was immediately centrifuged at $12,000 \times \mathrm{g}$ for $5 \mathrm{~min}$ at $4^{\circ} \mathrm{C}$. The supernatant was collected and serotonin release was measured with a serotonin ELISA kit (Labor Diagnostika Nord GmbH \& Co, Nordhorn, Germany) according to the manufacturer's instructions.

2.10. Measurement of Thromboxane $B_{2}$ Formation. Washed platelets $\left(3 \times 10^{8} / \mathrm{mL}\right)$ were pre-incubated with or without MAE for $2 \mathrm{~min}$ at $37^{\circ} \mathrm{C}$ in the presence of $1 \mathrm{mM} \mathrm{CaCl}$ and then stimulated with $2.5 \mu \mathrm{g} / \mathrm{mL}$ collagen for $5 \mathrm{~min}$. The reactions were terminated by adding ice-cold $2.5 \mathrm{mM}$ EDTA and $100 \mu \mathrm{M}$ indomethacin. After centrifugation at $12,000 \times \mathrm{g}$ for $3 \mathrm{~min}$ at $4^{\circ} \mathrm{C}$, the supernatant was collected and the concentration of $\mathrm{TXB}_{2}$ was measured using a $\mathrm{TXB}_{2}$ EIA kit according to the manufacturer's protocol.

2.11. Immunoblotting. Platelet suspensions $\left(3 \times 10^{8} / \mathrm{mL}\right)$ were pre-incubated with MAE or vehicle $(0.1 \%(\mathrm{v} / \mathrm{v})$ DMSO) at $37^{\circ} \mathrm{C}$ for $2 \mathrm{~min}$. Platelet activation was induced by the addition of $2.5 \mu \mathrm{g} / \mathrm{mL}$ collagen and the reaction was allowed to proceed for $5 \mathrm{~min}$. After terminating the reaction, lysates were then prepared by solubilizing and centrifuging the platelets in sample buffer $(0.125 \mathrm{M}$ Tris- $\mathrm{HCl}, \mathrm{pH} 6.8 ; 2 \%$ SDS, $2 \% \beta$-mercaptoethanol, $20 \%$ glycerol, $0.02 \%$ bromophenol blue, $1 \mu \mathrm{g} / \mathrm{mL}$ phenylmethylsulfonyl fluoride (PMSF), $2 \mu \mathrm{g} / \mathrm{mL}$ aprotinin, $1 \mu \mathrm{g} / \mathrm{mL}$ leupeptin, and $1 \mu \mathrm{g} / \mathrm{mL}$ pepstatin A). Protein concentration was determined using a BCA assay (PRO-MEASURE; iNtRON Biotechnology, Seoul, Republic of Korea). Total cell proteins $(30 \mu \mathrm{g})$ from the platelet lysate were resolved by $10 \%$ SDS-PAGE and transferred to nitrocellulose membranes in transfer buffer $(25 \mathrm{mM}$ Tris, pH 8.5; $0.2 \mathrm{M}$ glycine, and 20\% methanol). The membranes were blocked in TBS-T containing 5\% nonfat dry milk and incubated with primary antibody diluted in a blocking solution. The blots were then incubated with horseradish peroxidase-conjugated secondary antibody. Antibody binding was visualized using enhanced chemiluminescence (iNtRON Biotechnology, Seoul, Republic of Korea).

2.12. Assessment of Fibrinogen Binding to Integrin $\alpha_{I I b} \beta_{3}$. Fibrinogen Alexa Fluor 488 conjugate binding to washed platelets was quantified by flow cytometry. Briefly, washed platelets $\left(3 \times 10^{8} / \mathrm{mL}\right)$ were pre-incubated for $2 \mathrm{~min}$ with various concentrations of MAE at room temperature in the presence of $0.1 \mathrm{mM} \mathrm{CaCl}_{2}$. The platelets were then stimulated with collagen for $5 \mathrm{~min}$, immediately incubated thereafter with fibrinogen Alexa Fluor $488(20 \mu \mathrm{g} / \mathrm{mL})$ for $5 \mathrm{~min}$, and finally fixed with $0.5 \%$ paraformaldehyde at $4{ }^{\circ} \mathrm{C}$ for $30 \mathrm{~min}$. The platelets were pelleted by centrifugation at $2,000 \times \mathrm{g}$ at $4^{\circ} \mathrm{C}$ and resuspended in $500 \mu \mathrm{L}$ PBS. Since the activation of integrin $\alpha_{\mathrm{IIb}} \beta_{3}$ is largely dependent on the generation of $\mathrm{Ca}^{2+}$, nonspecific binding of fibrinogen to integrin $\alpha_{\mathrm{IIb}} \beta_{3}$ was measured by assessing fibrinogen binding in the presence of the calcium chelator EGTA $(1 \mathrm{mM})$. The fluorescence of each platelet sample was analyzed using a FACS Calibur cytometer (BD Biosciences, San Jose, CA, USA), and data were analyzed using CellQuest software (Becton Dickinson Immunocytometry Systems, San Jose, CA, USA). 
2.13. MAE Effect on Thrombus Formation in Arteriovenous Shunt Thrombosis Model In Vivo. The in vivo antithrombotic activity of MAE was evaluated in a rat arterio-venous shunt thrombosis model [28]. Rats were given orally administered $400 \mathrm{mg} / \mathrm{kg}, 200 \mathrm{mg} / \mathrm{kg}$, and $100 \mathrm{mg} / \mathrm{kg} \mathrm{MAE}$ which were dissolved in $0.25 \%$ carboxymethylcellulose (CMC, Sigma, USA) solution at the same time of day for 3 consecutive days by gavage. The shunt thrombosis model was tested $2 \mathrm{~h}$ after the last administration. For each test, different batches of six rats were used. After anaesthesia with Urethane $(1.25 \mathrm{~g} / \mathrm{kg}$ i.p) (Sigma, USA), an $8 \mathrm{~cm}$ polyethylene tube was inserted between the left jugular vein and the right carotid artery. The saline-filled shunt was assembled by connecting two cannulae with a slightly curved $6 \mathrm{~cm}$ long tygon tubing (internal diameter $2 \mathrm{~mm}$ ) containing a $5 \mathrm{~cm}$ long cotton thread (diameter $0.25 \mathrm{~mm}$ ) which had been scraped with a scalpel blade to render it more thrombogenic. The extracorporeal circulation was maintained for $15 \mathrm{~min}$, during which time a thrombus adheres to the cotton thread. The shunt was then removed and the thread with its associated thrombus was withdrawn and immediately weighed. The thrombus wet weight was determined by subtracting from the value obtained the weight of the dry $5 \mathrm{~cm}$ cotton thread determined previously.

2.14. Statistics. Data were analyzed with a one-way analysis of variance followed by a post hoc Dunnett's test in order to measure statistical significance of the differences observed (SAS Institute Inc., Cary, NC, USA). All data are presented as the mean \pm standard error of the mean (SEM). $P$ values of 0.05 or less were considered to be statistically significant.

\section{Results}

3.1. Chromatographic Separation of M. alba Extract. As shown Figure 1, high performance liquid chromatographic (HPLC) analysis of MAE revealed rutin and isoquercetin. The MAE contained $2.83 \pm 0.15 \mathrm{mg} / \mathrm{g}$ for rutin and $8.18 \pm$ $2.4 \mathrm{mg} / \mathrm{g}$ for isoquercetin, identified at a retention time of approximately $23.8 \mathrm{~min}$ and $24.7 \mathrm{~min}$, respectively.

3.2. Inhibitory Effect of MAE on Collagen-Induced Platelet Aggregation. In the beginning of those studies, we have evaluated whether MAE affected various ligands (ADP-, collagen- and thrombin) induced platelet aggregation. As shown in Figure 2(a), MAE only inhibited collagen-induced platelet aggregation but not in ADP- and thrombin-induced platelet aggregation. In the previous studies [29], we have found that $2.5 \mu \mathrm{g} / \mathrm{mL}$ of collagen, $10 \mu \mathrm{M}$ of ADP, and $0.1 \mathrm{U} / \mathrm{mL}$ of thrombin induced full activation and aggregation of rat platelet. Therefore, we have employed collagen $(2.5 \mu \mathrm{g} / \mathrm{mL})$ as a ligand to induce platelet aggregation in following studies. Figure 2 shows that MAE inhibited collagen$(2.5 \mu \mathrm{g} / \mathrm{mL})$ induced platelet aggregation in concentrationdependent manner.

3.3. Effect of MAE on Intracellular Calcium Ion Concentration. It is well known that intracellular calcium ion $\left(\left[\mathrm{Ca}^{2+}\right]_{i}\right)$ takes a pivotal role in the activation of downstream signaling molecules in platelet aggregation induced by a ligand such as collagen. Therefore, we have investigated whether MAE affect the $\left(\left[\mathrm{Ca}^{2+}\right]_{i}\right)$ mobilization induced by $2.5 \mu \mathrm{g} / \mathrm{mL}$ collagen. Collagen induced the massive amount of calcium mobilization by up to $631.7 \pm 46.7 \mathrm{nM}$, which was significantly and concentration-dependently inhibited by MAE (Figure 3).

3.4. Effects of MAE on the Granule Release. In the following studies, we have examined whether the extract modulated the secretion of granule contents such as ATP and serotonin which can activate platelets themselves acting as autacoids. Collagen $(2.5 \mu \mathrm{g} / \mathrm{mL})$ considerably induced ATP release from dense granule by 3 -fold in comparison with resting platelets. As depicted in Figure 4(a), MAE dose-dependently repressed collagen- $(2.5 \mu \mathrm{g} / \mathrm{mL})$ induced ATP release. In order to confirm the MAE's effect on dense granule, we have chosen another marker molecule serotonin in dense contents. As expected, MAE potently and concentration-dependently inhibited serotonin release which was induced by $2.5 \mu \mathrm{g} / \mathrm{mL}$ collagen (Figure 4(b)).

3.5. Effects of MAE on TXA2 Formation. We next investigated whether MAE affected TXA2 formation in collagen-activated platelets. TXA2 is another marker molecule in the initial activation of ligand binding to cognate receptor. In addition, it acts as an agonist against platelet own receptor, which, therefore, is named "autocoid." TXB2 is stable metabolite of TXA2 and thus TXB2 formation was measured. Figure 5 displayed that MAE significantly inhibited TXA2 formation in collagen-activated platelets.

3.6. Effects of MAE on the Phosphorylation of MAPKs and $A k t$. We next investigated whether MAE affected the phosphorylation of mitogen-activated protein kinase (MAPK), including extracellular-signal regulated kinase 1/2 (ERK1/2), p38 MAPK, and c-Jun N-terminal kinase (JNK). In previous studies $[26,30]$, we have shown that all these MAPKs were expressed and phosphorylated by ligands such as ADP and collagen. Our immunoblot analysis revealed that MAE potently inhibited collagen-induced ERK phosphorylation but marginally repressed collagen-induced JNK phosphorylation (Figure 7). However, collagen-induced p38 MAPK phosphorylation was not affected by the extract treatment. In addition, ligand binding to cognate receptor has been shown to activate phosphatidylinositol 3-kinase (PI3K) and Akt, which target the glycogen synthase kinase (GSK) $3 \beta$ as an Akt effecter. Therefore, we have investigated whether MAE modulated collagen-induced Akt activation. As depicted in Figure 7(b), MAE potently and concentration-dependently suppressed Akt phosphorylation which was activated by collagen.

3.7. Effects of MAE on the Integrin $\alpha_{I I b} \beta_{3}$ Activation. In order to complete platelet aggregation stably, outside-in signaling pathway should be activated, as determined with fibrinogen binding to active integrin $\alpha_{\mathrm{IIb}} \beta_{3}$.

The influence of MAE on integrin $\alpha_{\mathrm{IIb}} \beta_{3}$ activation was studied in collagen-stimulated platelets. As shown in 


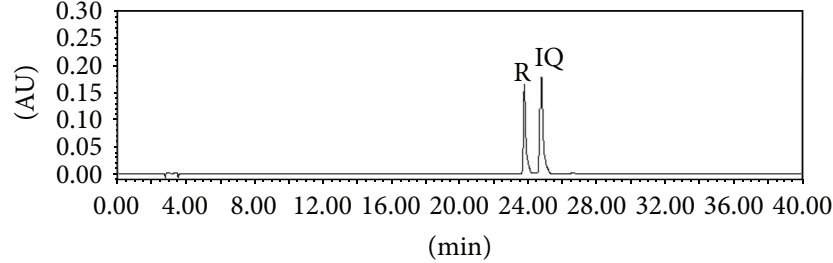

(a)

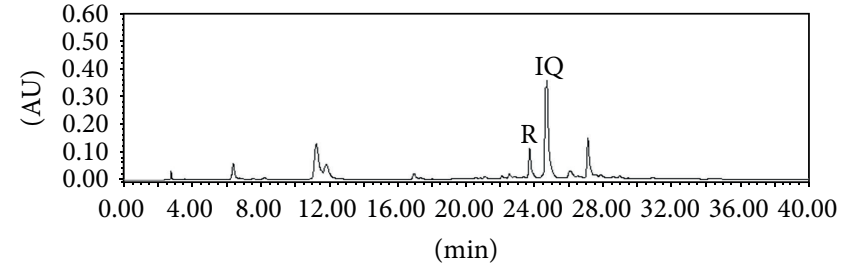

(b)

FIGURE 1: HPLC chromatogram of standard mixture (a) and Morus alba leaves extracts at $350 \mathrm{~nm}$. The chromatographic analysis was performed as described in the "Section 2" Identification was based on retention time and UV spectra by comparison with commercial standards. R: rutin; Q: isoquercetin.

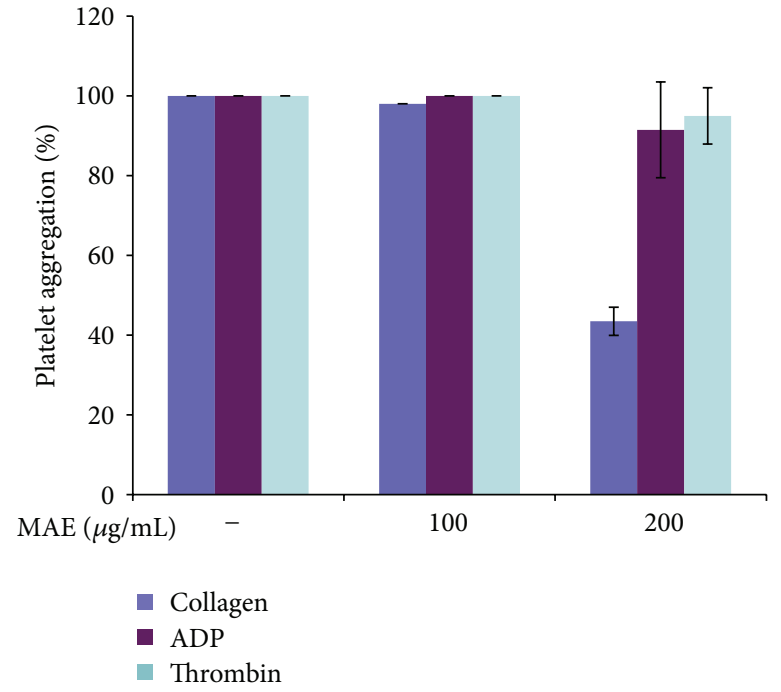

(a)

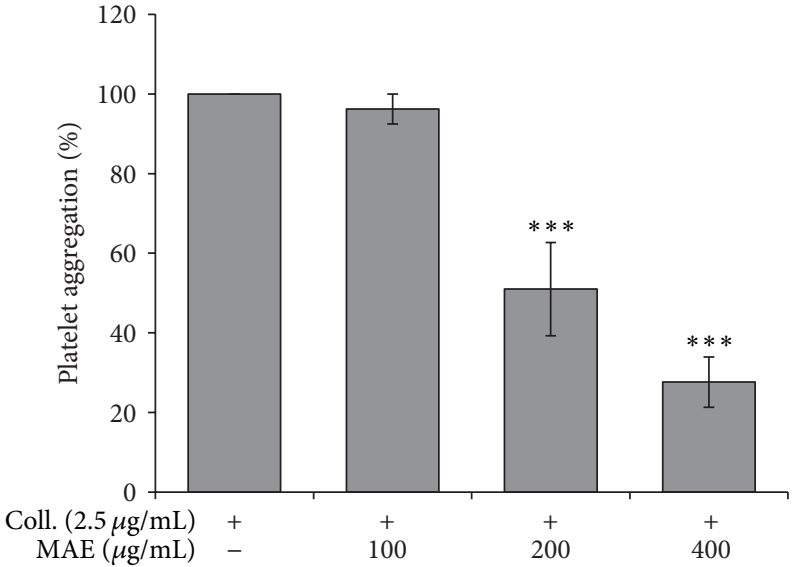

(b)

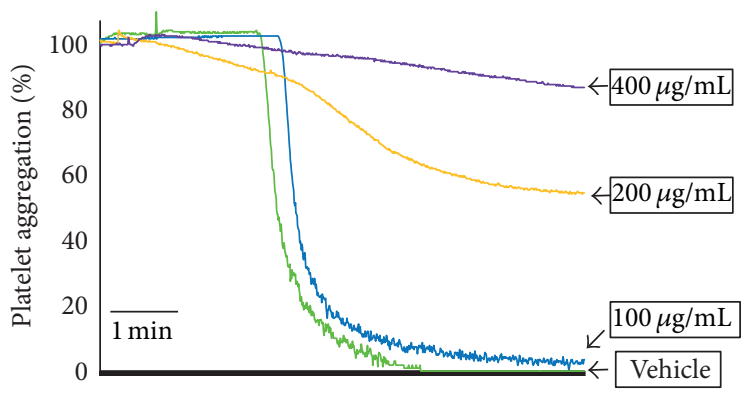

(c)

Figure 2: The inhibitory effect of Morus alba leaves extracts (MAE) on platelet aggregation induced by collagen. Platelets $\left(3 \times 10^{8} / \mathrm{mL}\right)$ were preincubated with or without MAE $(100-400 \mu \mathrm{g} / \mathrm{mL})$ in the presence of $1 \mathrm{mM} \mathrm{CaCl}$ for $2 \mathrm{~min}$ at $37^{\circ} \mathrm{C}$. The platelet aggregation was then induced by $2.5 \mu \mathrm{g} / \mathrm{mL}$ collagen, $10 \mu \mathrm{M}$ ADP, and $0.1 \mathrm{U} / \mathrm{mL}$ thrombin. The extent of platelet aggregation was measured with an aggregometer. The aggregation reaction was terminated after $5 \mathrm{~min}$, and the percent aggregation rate was calculated. Each graph shows the mean \pm SEM of at least four independent experiments. ${ }^{* * *} P<0.001$ compared to the agonist control.

Figure 6, collagen $(2.5 \mu \mathrm{g} / \mathrm{mL})$ increased the fibrinogen binding to active integrin $\alpha_{\mathrm{II}} \beta_{3}$, whereas resting platelets did not activate the integrin.

The plant extracts reduced collagen- $(2.5 \mu \mathrm{g} / \mathrm{mL})$ induced fibrinogen binding to integrin $\alpha_{\mathrm{IIb}} \beta_{3}$ in concentrationdependent manner (Figure 6).
3.8. Effect of MAE on Arteriovenous Shunt Thrombosis. The AV-shunt thrombosis model has been commonly used to assess antithrombotic effects. Compared to the control, a 3-day oral treatment with MAE decreased thrombus weight in the rat arteriovenous shunt thrombosis model. As shown in Figure 8, after oral administration of 100, 200, 


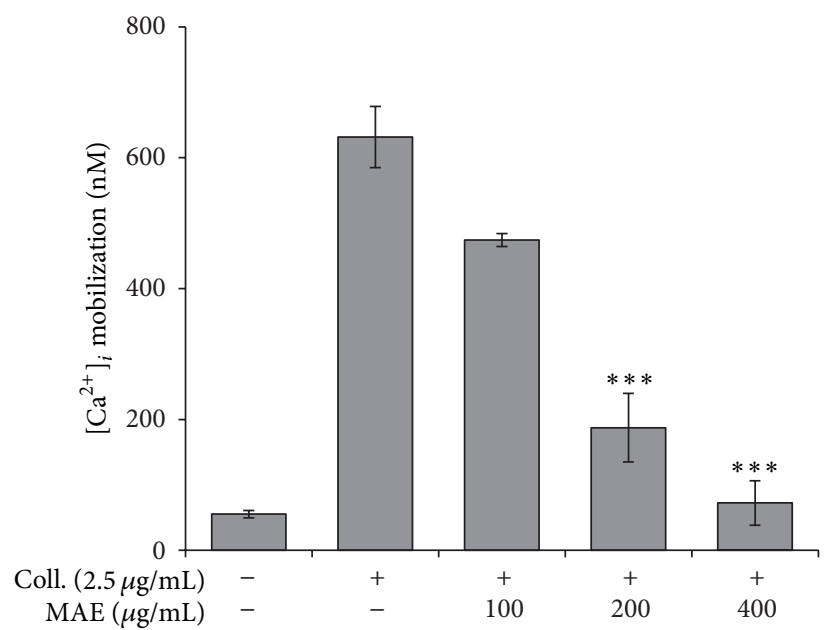

FIGURE 3: The inhibitory effect of Morus alba leaves extracts (MAE) on $\left[\mathrm{Ca}^{2+}\right]_{i}$ increased by collagen. Washed platelets $\left(3 \times 10^{8} / \mathrm{mL}\right)$ were incubated with a calcium fluorophore $\left(5 \mu \mathrm{M} \text {, Fura-2/AM) and stimulated with collagen }(2.5 \mu \mathrm{g} / \mathrm{mL}) \text {. [Ca }{ }^{2+}\right]_{i}$ was then measured as described in Section 2. The results are presented as the mean \pm SEM of at least three independent experiments. ${ }^{* * *} P<0.001$ compared to the agonist control.

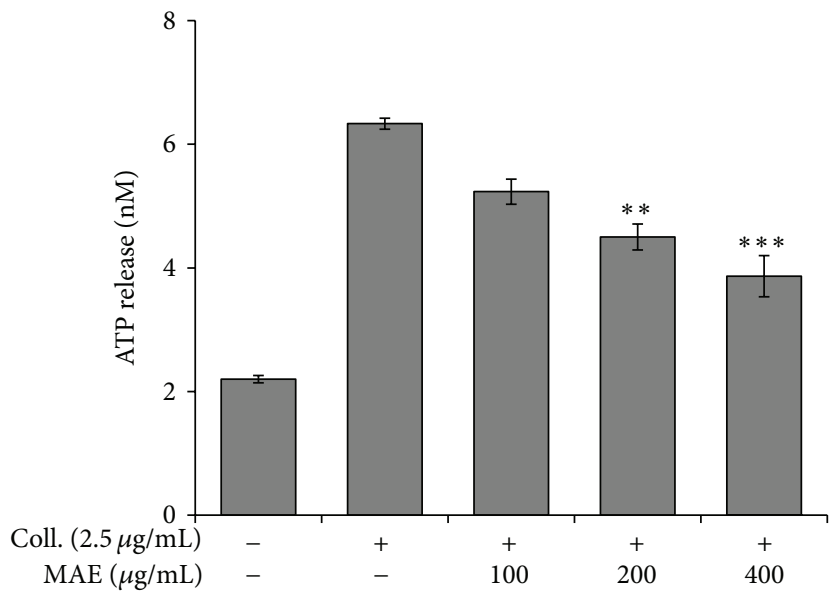

(a)

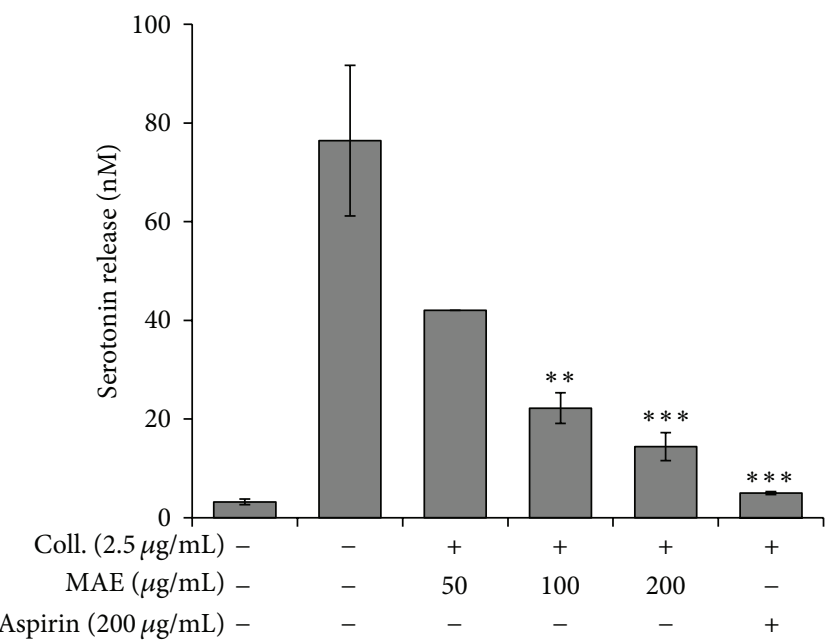

(b)

FIgURE 4: Effects of Morus alba leaves extracts (MAE) on granule secretion from the collagen-stimulated platelets. Washed platelets $(3 \times$ $10^{8} / \mathrm{mL}$ ) were pre-incubated with MAE at the indicated concentrations and stirred in an aggregometer for 2 min prior to stimulation with $2.5 \mu \mathrm{g} / \mathrm{mL}$ collagen for $5 \mathrm{~min}$. The reaction was terminated, and an ATP release assay (a) and serotonin release assay (b) were carried out as described in Materials and Methods. Bar graphs show the mean \pm SEM of at least four independent experiments. ${ }^{* *} P<0.01$ and ${ }^{* * *} P<0.001$ compared to the agonist control.

and $400 \mathrm{mg} / \mathrm{kg} /$ day, MAE significantly and dose-dependently decreased the thrombus weight by $52.3 \%(P<0.001)$, 28.3\% $(P<0.01)$, and 19.1\% $(P<0.05)$ compared to vehicle control, respectively. Rivaroxaban which was used as a positive control is an oral anticoagulant for the prevention and treatment of thrombosis mediated conditions [31]. Rivaroxaban $5 \mathrm{mg} / \mathrm{kg} /$ day was different from control $(P<$ $0.001)$ and MAE $100 \mathrm{mg} / \mathrm{kg} /$ day $(P<0.05)$, but not from MAE $200 \mathrm{mg} / \mathrm{kg} /$ day and $400 \mathrm{mg} / \mathrm{kg} /$ day.

\section{Discussion}

These results show that in vitro the ethanol extract of $M$. alba L. leaf (MAE) inhibits collagen-induced platelet aggregation in a concentration-dependent manner. In order to elucidate the mechanism of inhibitory activities of MAE extract, we have analyzed downstream signaling as follows intracellular calcium concentration, dense granule secretions, protein phosphorylations (e.g., MAPKs and Akt), and integrin signaling. In addition, we next investigated whether this 


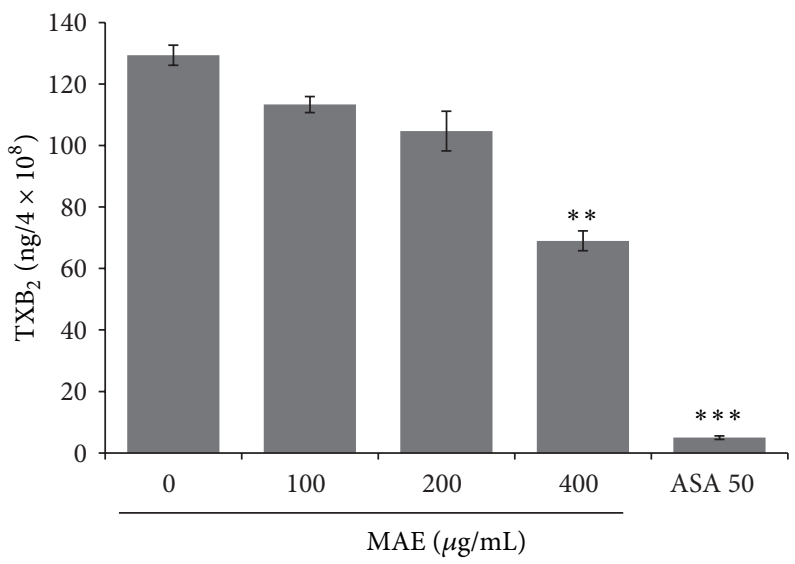

Figure 5: Effects of Morus alba leaves extracts (MAE) on TXA2 formation from the collagen-stimulated platelets. Washed platelets $(3 \times$ $10^{8} / \mathrm{mL}$ ) were pre-incubated with MAE at the indicated concentrations and stirred in an aggregometer for 2 min prior to stimulation with $2.5 \mu \mathrm{g} / \mathrm{mL}$ collagen. The reaction was terminated at $5 \mathrm{~min}$, and TXA2 formation was performed as described in Materials and Methods. Bar graphs show the mean \pm SEM of triplicate independent experiments. ${ }^{* *} P<0.01$ and ${ }^{* * *} P<0.001$ compared to the agonist control.

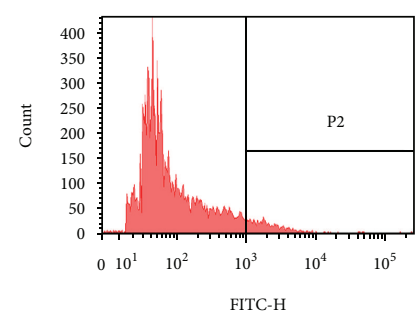

(A)

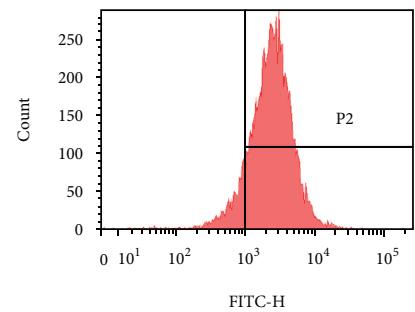

(C)

(E)

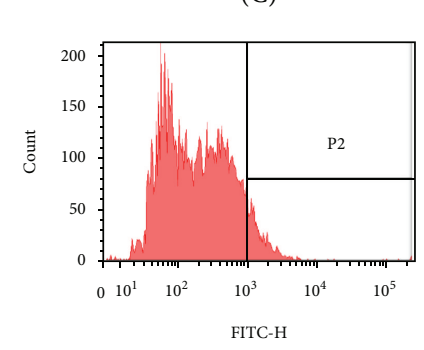

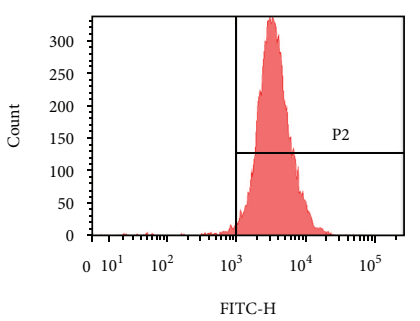

(B)

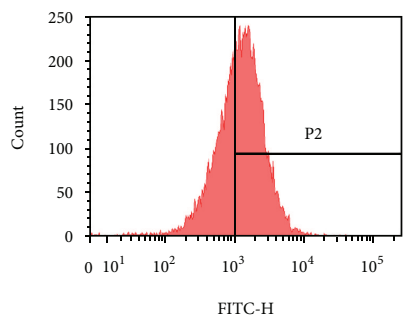

(D)

(a)

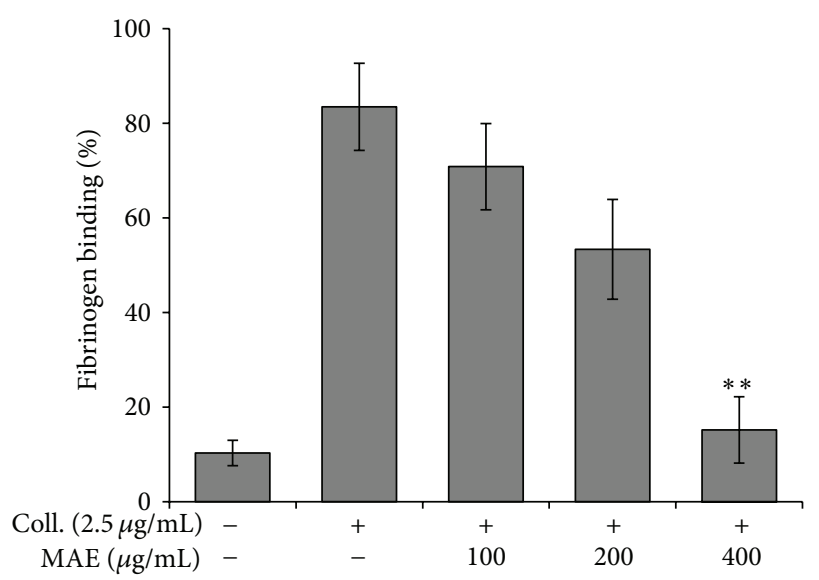

(b)

FIgURE 6: Effects of Morus alba leaves extracts (MAE) on fibrinogen binding to integrin $\alpha_{\text {IIb }} \beta_{3}$ in ADP-activated platelets. The inhibitory effects of MAE on fibrinogen binding to integrin $\alpha_{\mathrm{IIb}} \beta_{3}$ in collagen-activated platelets were measured by flow cytometry (A). Washed platelets $\left(3 \times 10^{8} / \mathrm{mL}\right)$ were pretreated with vehicle (DMSO) or MAE at concentrations ranging from $100 \mu \mathrm{g} / \mathrm{mL}$ to $400 \mu \mathrm{g} / \mathrm{mL}$. Collagen was then incubated with human fibrinogen labeled with Alexa Fluor $488(20 \mu \mathrm{g} / \mathrm{mL})$ for $5 \mathrm{~min}$. The cells were subsequently fixed with $0.5 \%$ paraformaldehyde at $4^{\circ} \mathrm{C}$ for $30 \mathrm{~min}$. Graphs showing fluorescent intensity present the data from one experiment but are representative of four independent trials. Data are expressed as the mean fluorescence intensity (MFI) of fibrinogen-positive platelets. Each graph presents the results expressed as percent of gated (a). ${ }^{* *} P<0.01$ compared to the agonist control. 

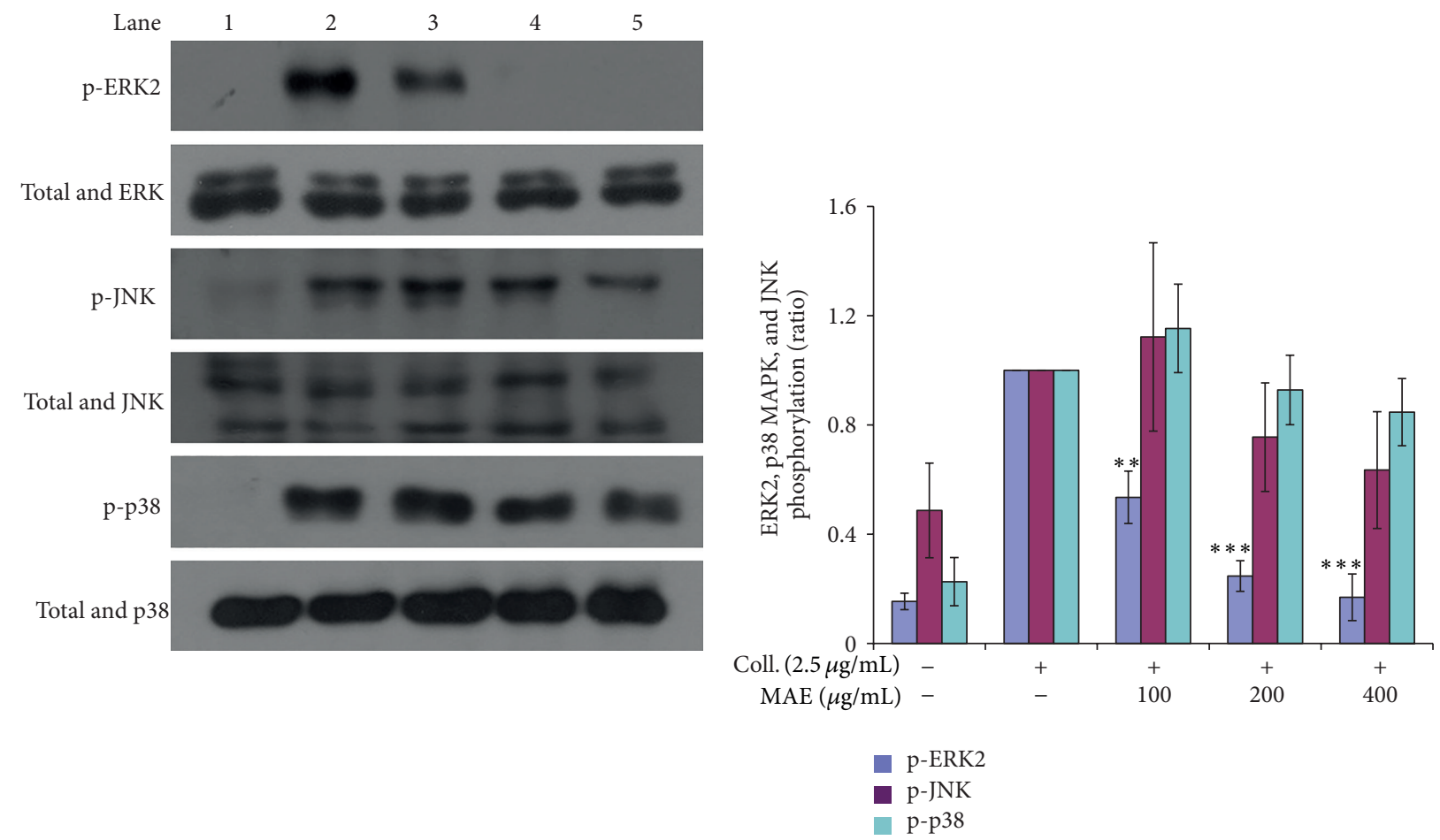

(a)
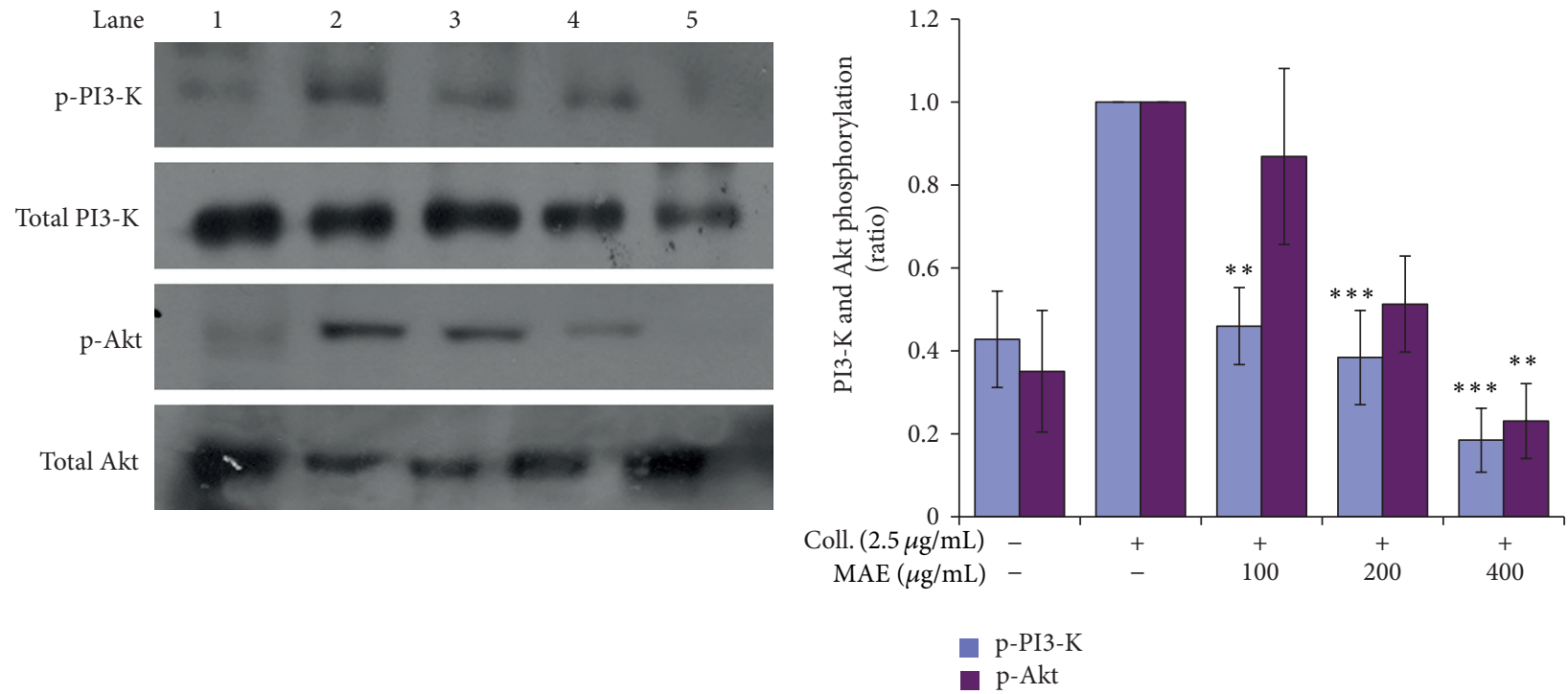

(c)

(d)

FIGURE 7: Effects of Morus alba leaves extracts (MAE) on collagen-induced phosphorylation of MAPKs, PI3K, and Akt. Washed platelets (3× $10^{8} / \mathrm{mL}$ ) were pre-incubated for 2 min with vehicle or MAE at the indicated concentration. The platelets were then stimulated with $10 \mu \mathrm{M}$ ADP for $5 \mathrm{~min}$ at $37^{\circ} \mathrm{C}$. After terminating the reactions, total cell proteins were extracted. The proteins were separated by SDS-PAGE and transferred onto nitrocellulose membranes. The membranes were then probed with antibodies against phospho-p44/42, p44/42, phospho-p38, p38, phospho-SAPK/JNK, and $\beta$-actin ((a), (b)) and phospho-PI3K, phospho-Akt, PKA $\alpha / \beta / \gamma$ cat, and $\beta$-actin ((c), (d)). Antibody binding was visualized by chemiluminescence. All immunoblots are representative of three or four independent experiments. ${ }^{* *} P<0.01$ and ${ }^{* * *} P<0.001$ versus vehicle control.

efficacy of MAE in vitro is implemented in in vivo application. That is, the extract given orally to rats for 3 days dosedependently decreased thrombus weight in a common model of arterial thrombosis. To the best of our knowledge this is the first report to demonstrate the effects on platelet aggregation and thrombosis.

Upon the ligand binding to platelet membrane receptors, $\left[\mathrm{Ca}^{2+}\right]_{i}$ plays an important role in the initial activation of 


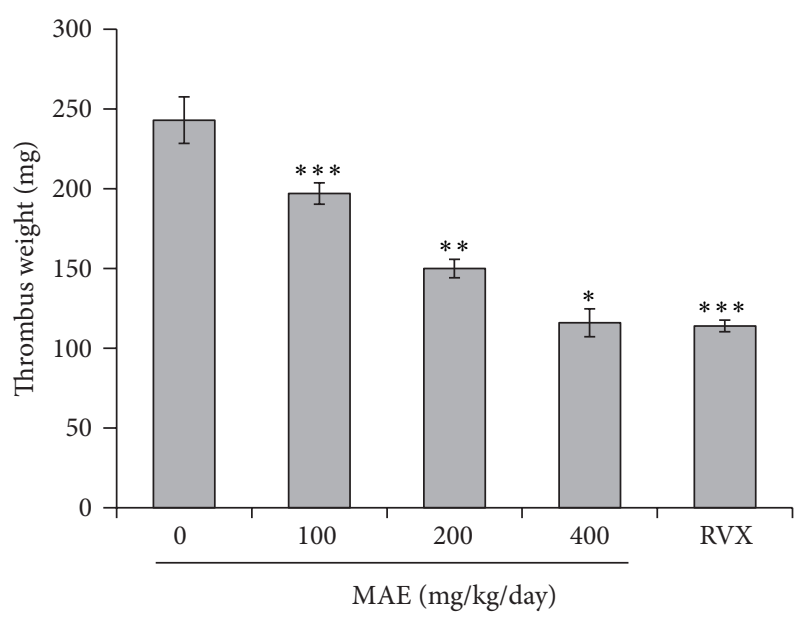

Figure 8: Effect of Morus alba leaves extracts (MAE) on thrombus formation in rats. The procedures for the AV-shunt model are described in the Section 2. Thrombus weight in an arteriovenous shunt was measured at $2 \mathrm{~h}$ after administration of 3-day treatment with $0.25 \%$ carboxymethylcellulose solution (control), ethanol extract of Morus alba L. leaves (MAE) 100, 200 or $400 \mathrm{mg} / \mathrm{kg} / \mathrm{day}$, and positive control (rivaroxaban, RVX) $5 \mathrm{mg} / \mathrm{kg} /$ day. Data are shown as mean \pm S.D. ${ }^{*} P<0.05,{ }^{* *} P<0.01,{ }^{* * *} P<0.001$ versus vehicle control.

platelet and subsequent platelet aggregation. Upregulation of $\left[\mathrm{Ca}^{2+}\right]_{i}$ is due to both calcium influx from extracellular fluid and calcium mobilization from intracellular pools, such as dense tubular system and mitochondria. Although unknown is the source of $\left[\mathrm{Ca}^{2+}\right]_{i}$, collagen dramatically escalates intracellular calcium concentration which is significantly and concentration-dependently reduced by MAE. In addition, we did not determined whether MAE modulate either calcium influx in platelet membrane or inositol-1,4,5-trisphosphate (IP3) receptor on platelet organelles. However, MAE potently blocked collagen-induced $\left[\mathrm{Ca}^{2+}\right]_{i}$ upregulation which is at least main cause of antiplatelet activity.

Mammalian platelets devoid of nucleus and basically transcriptional and translational activities are limited. Although platelet transcription factors such as nuclear factor kappa $\mathrm{B}(\mathrm{NF}-\kappa \mathrm{B})$ are some reported $[32,33]$, it is largely understood that new functional protein synthesis is limited. Therefore, granule substances take a pivotal role in the platelet activation and aggregation due to its biological and functional significance. For example, dense granules enclosed ATP, ADP, serotonin and $\mathrm{Ca}^{2+}$. They act as an autacoid (e.g., self-activator) or an important modulator in the downstream signaling. Therefore, the MAE's antiplatelet activity might be due to the potent inhibition of granule secretion (i.e., $\mathrm{Ca}^{2+}$, ATP, and serotonin) (Figure 9).

The activation of integrin $\alpha_{\text {IIb }} \beta_{3}$ is plays an important role in the final step of platelet activation and aggregation, which is named as inside-out signaling. That is, the phosphorylation of integrin $\alpha_{\text {IIb }} \beta_{3}$ is able to bind to another phosphorylated integrin $\alpha_{\mathrm{IIb}} \beta_{3}$, which is mediated via fibrinogen-like bridge network. Finally, strict and stable blood thrombus is being formed. Therefore, screening of pharmacological inhibitors is

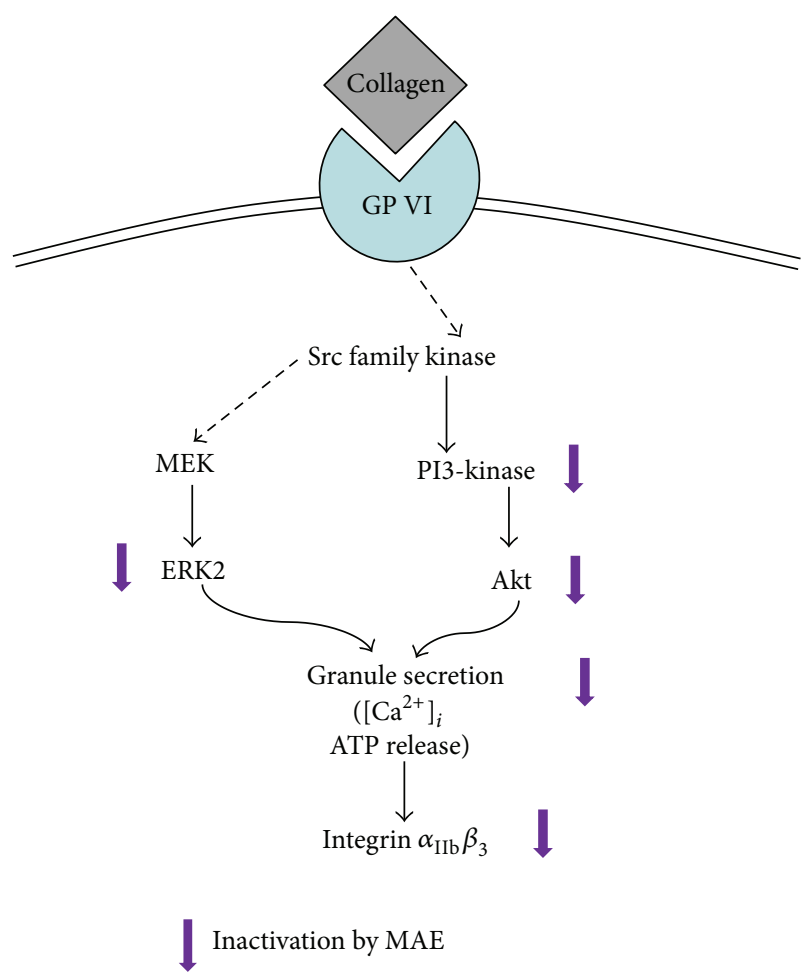

FIGURE 9: The summary of inhibitory effect of MAE in collageninduced platelet aggregation. GP VI: glycoprotein VI; MEK1 mitogen-activated protein kinase kinase; ERK2, extracellularregulated kinase 2 .

widely being investigated for antiplatelet and antithrombotic agents. At the moment, we insisted that MAE could be developed as antiplatelet or antithrombotic agents or functional food.

On the other hand, the phosphorylation of signaling molecules, including MAPKs (i.e., ERK1/2, p38 MAPK, and JNK) and PI3K/Akt is also crucial phase in outside-in and inside-out signaling of platelet aggregation. In our results, the collagen-induced phosphorylation of ERK and JNK was inhibited by MAE but not p38 MAPK. Although the role of ERK and JNK in platelet physiology is not clear, there are several evidences that they are involved in the activation of integrin $\alpha_{\mathrm{IIb}} \beta_{3}$ and $\mathrm{PLA}_{2} / \mathrm{TXA}_{2}$ pathways $[34,35]$. In addition, MAE blocked collagen-induced TXA2 production (Figure 5). This indicated that MAE blocked MAPK-integrin $\alpha_{\text {IIb }} \beta_{3}$ and $\mathrm{PLA}_{2} / \mathrm{TXA}_{2}$ routs and thus displayed potent antiplatelet activity.

On the other hand, PI3-K/Akt pathway plays important role in the platelet activation and aggregation. The receptor activation leads to the phosphorylation of PI3-K and subsequently activation and phosphorylation of Akt. Moreover, it is reported that signaling routes of PI3-K are involved in the transient activation of integrin $\alpha_{\mathrm{IIb}} \beta_{3}$. As shown in Figure 7(b), MAE significantly inhibited both PI3-K and Akt phosphorylation. However, at the moment, direct inhibition of MAE on either PI3-K or PI3-K and Akt is not clear, which remains to be elucidated in the future. 
Blood flow disturbances at sites of atherosclerotic plaque rupture promote platelet activation and arterial thrombus formation [36, 37]. In the present study, MAE significantly inhibited collagen-induced platelet aggregation in vitro and rat carotid artery thrombus formation in vivo. Therefore, MAE has potential to prevent thrombotic or cardiovascular disease.

MAE also inhibited serotonin and ATP secretion in a concentration-dependent manner. Serotonin and ATP can cause vasoconstriction of interarterial coronary collateral vessels, and they suggest that platelet activation in coronary arteries that are linked to collateral vessels has the potential to cause collateral vasoconstriction, thereby compromising blood flow to the dependent myocardium [38-40]. Therefore MAE might be used for prevention or treatment of myocardial infarction.

The butanol-soluble fraction from MAE showed the strongest inhibitory effect against collagen-induced platelet aggregation when compared with other fractions, hexane, ethyl acetate and water fractions of MAE. The finding indicates that active principles are medium polar, suggesting that alcoholic extract rather than water extract such as tea or beverage might be beneficial for cardiovascular.

In this study, from MAE we identified two quercetin glycosides, rutin and isoquercetin, which have been reported to be major components of $M$. alba leaf along with quercetin as major components in $M$. alba leaf $[18,41]$.

We also further evaluated the inhibitory effects of rutin and isoquercetin at high concentration of $400 \mu \mathrm{g} / \mathrm{mL}$ on collagen-induced platelet aggregation, but they slightly inhibited (Data not shown). Since their aglycone, quercetin, is known to inhibit strongly on platelet aggregation rabbit platelets induced by collagen, ADP, or arachidonic acid [26, 42 ], we also investigated its existence using its commercial standard but not identified on HPLC chromatogram; a standard quercetin was retained approximately at $34.6 \mathrm{~min}$ (data not shown), but any traceable peak was not appeared near the retention time as shown Figure 1. Further study would be required in order to identify the active compound(s).

\section{Conclusions}

In in vitro assays using freshly isolated rat platelets, the MAE showed significant inhibition of collagen-induced platelet aggregation, and these effects were also associated with reduced $\left[\mathrm{Ca}^{2+}\right]_{i}$, ATP and serotonin secretion, and integrin $\alpha_{\mathrm{IIb}} \beta_{3}$. In accordance with these enhanced in vitro antiplatelet activities, the extract showed enhanced antithrombotic effects in in vivo arterial thrombosis model. Thus, these results suggest that MAE can be a good candidate to an antiplatelet and antithrombotic agent.

\section{Conflict of Interests}

The authors declare that they have no conflict of interests.

\section{Acknowledgments}

This work was mainly supported by Discovery of Herbal Medicine for Prevention (K13202), the Korea Institute of
Oriental Medicine (KIOM) to the Ministry of Science, ICT \& Future Planning (MSIP), Korea. Additionally, this work was also partially supported by ICT Fusional Construction of Alternative Herbal Medicine Resources (K14410), Characterization of Native Biological Resources and Excavation of Alternative Herbal Medicine Resources (K14411), the Korea Institute of Oriental Medicine (KIOM) to the Ministry of Science, ICT \& Future Planning (MSIP), Korea.

\section{References}

[1] L. H. Lindholm and S. Mendis, "Prevention of cardiovascular disease in developing countries," The Lancet, vol. 370, no. 9589, pp. 720-722, 2007.

[2] A. Stoyioglou and M. R. Jaff, "Medical treatment of peripheral arterial disease: a comprehensive review," Journal of Vascular and Interventional Radiology, vol. 15, no. 11, pp. 1197-1207, 2004.

[3] E. Falk, "Plaque rupture with severe pre-existing stenosis precipitating coronary thrombosis. Characteristics of coronary atherosclerotic plaques underlying fatal occlusive thrombi," British Heart Journal, vol. 50, no. 2, pp. 127-134, 1983.

[4] J. T. Willerson, P. Golino, J. Eidt, W. B. Campbell, and L. M. Buja, "Specific platelet mediators and unstable coronary artery lesions. Experimental evidence and potential clinical implications," Circulation, vol. 80, no. 1, pp. 198-205, 1989.

[5] C. J. Pepine, "Residual risk for secondary ischemic events in patients with atherothrombotic disease: opportunity for future improvements in patient care," Annals of Medicine, vol. 42, no. 1, pp. 19-35, 2010.

[6] D. Varon and G. Spectre, "Antiplatelet agents," Hematology, pp. 267-272, 2009.

[7] C. Patrono, B. Coller, G. A. FitzGerald, J. Hirsh, and G. Roth, "Platelet-active drugs: the relationships among dose, effectiveness, and side effects: the Seventh ACCP Conference on Antithrombotic and Thrombolytic Therapy," Chest, vol. 126, no. 3, supplement, pp. 234S-264S, 2004.

[8] D. L. Bhatt and E. J. Topol, "Scientific and therapeutic advances in antiplatelet therapy," Nature Reviews Drug Discovery, vol. 2, no. 1, pp. 15-28, 2003.

[9] W. G. Eisert, "How to get from antiplatelet to antithrombotic treatment," American Journal of Therapeutics, vol. 8, no. 6, pp. 443-449, 2001.

[10] P. A. Gum, K. Kottke-Marchant, P. A. Welsh, J. White, and E. J. Topol, "A prospective, blinded determination of the natural history of aspirin resistance among stable patients with cardiovascular disease," Journal of the American College of Cardiology, vol. 41, no. 6, pp. 961-965, 2003.

[11] S. H. Rezkalla and M. Benz, "Antiplatelet therapy from clinical trials to clinical practice," Clinical Medicine \& Research, vol. 1, no. 2, pp. 101-104, 2003.

[12] J. Heo, Dongeuibogam, Bubin Publishers, Seoul, South Korea, 2012.

[13] F. B. Hu, "Plant-based foods and prevention of cardiovascular disease: an overview," The American Journal of Clinical Nutrition, vol. 78, no. 3, supplement, pp. 544S-551S, 2003.

[14] M.-Y. Yang, C.-N. Huang, K.-C. Chan, Y.-S. Yang, C.-H. Peng, and C.-J. Wang, "Mulberry leaf polyphenols possess antiatherogenesis effect via inhibiting LDL oxidation and foam cell formation," Journal of Agricultural and Food Chemistry, vol. 59, no. 5, pp. 1985-1995, 2011. 
[15] J. Naowaboot, P. Pannangpetch, V. Kukongviriyapan, U. Kukongviriyapan, S. Nakmareong, and A. Itharat, "Mulberry leaf extract restores arterial pressure in streptozotocin-induced chronic diabetic rats," Nutrition Research, vol. 29, no. 8, pp. 602608, 2009.

[16] N.-C. Yang, K.-Y. Jhou, and C.-Y. Tseng, "Antihypertensive effect of mulberry leaf aqueous extract containing $\gamma$-aminobutyric acid in spontaneously hypertensive rats," Food Chemistry, vol. 132, no. 4, pp. 1796-1801, 2012.

[17] K.-S. Oh, S. Y. Ryu, S. Lee et al., "Melanin-concentrating hormone-1 receptor antagonism and anti-obesity effects of ethanolic extract from Morus alba leaves in diet-induced obese mice," Journal of Ethnopharmacology, vol. 122, no. 2, pp. 216220, 2009.

[18] T. Katsube, M. Yamasaki, K. Shiwaku et al., "Effect of flavonol glycoside in mulberry (Morus alba L.) leaf on glucose metabolism and oxidative stress in liver in diet-induced obese mice," Journal of the Science of Food and Agriculture, vol. 90, no. 14, pp. 2386-2392, 2010.

[19] J. M. Park, H. Y. Bong, H. I. Jeong, Y. K. Kim, J. Y. Kim, and O. Kwon, "Postprandial hypoglycemic effect of mulberry leaf in Goto-Kakizaki rats and counterpart control Wistar rats," Nutrition Research and Practice, vol. 3, no. 4, pp. 272-278, 2009.

[20] L. S. Hsu, H. H. Ho, M. C. Lin, C. C. Chyau, J. S. Peng, and C. J. Wang, "Mulberry water extracts (MWEs) ameliorated carbon tetrachloride-induced liver damages in rat," FFood and Chemical Toxicology, vol. 50, no. 9, pp. 3086-3093, 2012.

[21] J. Du, Z.-D. He, R.-W. Jiang, W.-C. Ye, H.-X. Xu, and P. P.-H. But, "Antiviral flavonoids from the root bark of Morus alba L," Phytochemistry, vol. 62, no. 8, pp. 1235-1238, 2003.

[22] W. Wang, Y. Zu, Y. Fu, and T. Efferth, "In vitro antioxidant and antimicrobial activity of extracts from Morus alba L. leaves, stems and fruits," American Journal of Chinese Medicine, vol. 40, no. 2, pp. 349-356, 2012.

[23] J. J. Lee, H. Yang, Y. M. Yoo et al., "Morusinol extracted from Morus alba inhibits arterial thrombosis and modulates platelet activation for the treatment of cardiovascular disease," Journal of Atherosclerosis and Thrombosis, vol. 19, no. 6, pp. 516-522, 2012.

[24] D.-H. Lee, H.-J. Cho, H.-Y. Kang, M. H. Rhee, and H.-J. Park, "Total saponin from Korean red ginseng inhibits thromboxane $\mathrm{A}_{2}$ production associated microsomal enzyme activity in platelets," Journal of Ginseng Research, vol. 36, no. 1, pp. 40-46, 2012.

[25] J. Y. Park, W. J. Oh, M. J. Kim et al., "Mechanism of anti-platelet activity of Oligoporus tephroleucus oligoporin A: involvement of extracellular signal-regulated kinase phosphorylation and cyclic nucleotide elevation," Platelets, vol. 23, no. 5, pp. 376-385, 2012.

[26] W. J. Oh, M. Endale, S. C. Park, J. Y. Cho, and M. H. Rhee, "Dual roles of quercetin in platelets: phosphoinositide-3-kinase and MAP kinases inhibition, and cAMP-dependent vasodilator-stimulated phosphoprotein stimulation," Evidence-Based Complementary and Alternative Medicine, vol. 2012, Article ID 485262, 2012.

[27] J. Schaeffer and M. P. Blaustein, "Platelet free calcium concentrations measured with fura- 2 are influenced by the transmembrane sodium gradient," Cell Calcium, vol. 10, no. 2, pp. 101-113, 1989.

[28] T. Umetsu and K. Sanai, "Effect of 1-methyl-2-mercapto-5-(3pyridyl)-imidazole (KC-6141), an anti-aggregating compound, on experimental thrombosis in rats," Thrombosis and Haemostasis, vol. 39, no. 1, pp. 74-83, 1978.

[29] S. D. Kim, I.-K. Lee, W. M. Lee et al., “The mechanism of antiplatelet activity of davallialactone: involvement of intracellular calcium ions, extracellular signal-regulated kinase 2 and p38 mitogen-activated protein kinase," European Journal of Pharmacology, vol. 584, no. 2-3, pp. 361-367, 2008.

[30] J. Y. Park, M. Hong, Q. Jia et al., "Pistacia chinensis methanolic extract attenuated MAPK and akt phosphorylations in ADP stimulated rat platelets In vitro," Evidence-Based Complementary and Alternative Medicine, vol. 2012, Article ID 895729, 7 pages, 2012.

[31] T. C. Sarich, G. Peters, S. D. Berkowitz et al., "Rivaroxaban: a novel oral anticoagulant for the prevention and treatment of several thrombosis-mediated conditions," Annals of the New York Academy of Sciences, vol. 1291, pp. 42-55, 2013.

[32] H.-S. Lee, S. D. Kim, W. M. Lee et al., "A noble function of BAY 11-7082: inhibition of platelet aggregation mediated by an elevated cAMP-induced VASP, and decreased ERK2/JNK1 phosphorylations," European Journal of Pharmacology, vol. 627, no. 1-3, pp. 85-91, 2010.

[33] A. Hachem, D. Yacoub, Y. Zaid, W. Mourad, and Y. Merhi, "Involvement of nuclear factor kappaB in platelet CD40 signaling," Biochemical and Biophysical Research Communications, vol. 425, no. 1, pp. 58-63, 2012.

[34] S. Gambaryan, A. Kobsar, N. Rukoyatkina et al., "Thrombin and collagen induce a feedback inhibitory signaling pathway in platelets involving dissociation of the catalytic subunit of protein kinase a from an NF $\kappa \mathrm{B}-\mathrm{I} \kappa \mathrm{B}$ complex," Journal of Biological Chemistry, vol. 285, no. 24, pp. 18352-18363, 2010.

[35] A. Garcia, H. Shankar, S. Murugappan, S. Kim, and S. P. Kunapuli, "Regulation and functional consequences of ADP receptor-mediated ERK2 activation in platelets," Biochemical Journal, vol. 404, no. 2, pp. 299-308, 2007.

[36] Z. Li, X. Xi, and X. Du, "A mitogen-activated protein kinasedependent signaling pathway in the activation of platelet integrin $\alpha \mathrm{IIb} \beta 3$," Journal of Biological Chemistry, vol. 276, no. 45, pp. 42226-42232, 2001.

[37] J. Chou, N. Mackman, G. Merrill-Skoloff, B. Pedersen, B. C. Furie, and B. Furie, "Hematopoietic cell-derived microparticle tissue factor contributes to fibrin formation during thrombus propagation," Blood, vol. 104, no. 10, pp. 3190-3197, 2004.

[38] S. R. Steinhubl and D. J. Moliterno, "The role of the platelet in the pathogenesis of atherothrombosis," American Journal of Cardiovascular Drugs, vol. 5, no. 6, pp. 399-408, 2005.

[39] L. M. Buja and J. T. Willerson, "Effects of serotonin and thromboxane $\mathrm{A}_{2}$ on the coronary collateral circulation," Journal of the American College of Cardiology, vol. 19, no. 3, pp. 694-695, 1992.

[40] D. H. Cowan, "Platelet adherence to collagen: role of prostaglandin-thromboxane synthesis," British Journal of Haematology, vol. 49, no. 3, pp. 425-434, 1981.

[41] P. Golino, L. M. Buja, Y. Sheng-Kun, J. McNatt, and J. T. Willerson, "Failure of nitroglycerin and diltiazem to reduce platelet-mediated vasoconstriction in dogs with coronary artery stenosis and endothelial injury: further evidence for thromboxane $\mathrm{A}_{2}$ and serotonin as mediators of coronary artery vasoconstriction in vivo," Journal of the American College of Cardiology, vol. 15, no. 3, pp. 718-726, 1990.

[42] G.-N. Kim and H.-D. Jang, "Flavonol content in the water extract of the mulberry (Morus alba L.) leaf and their antioxidant capacities," Journal of Food Science, vol. 76, no. 6, pp. C869C873, 2011. 


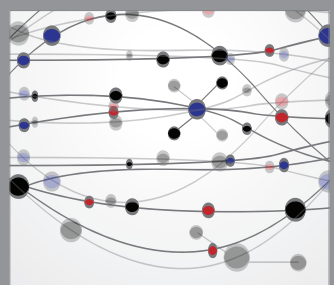

The Scientific World Journal
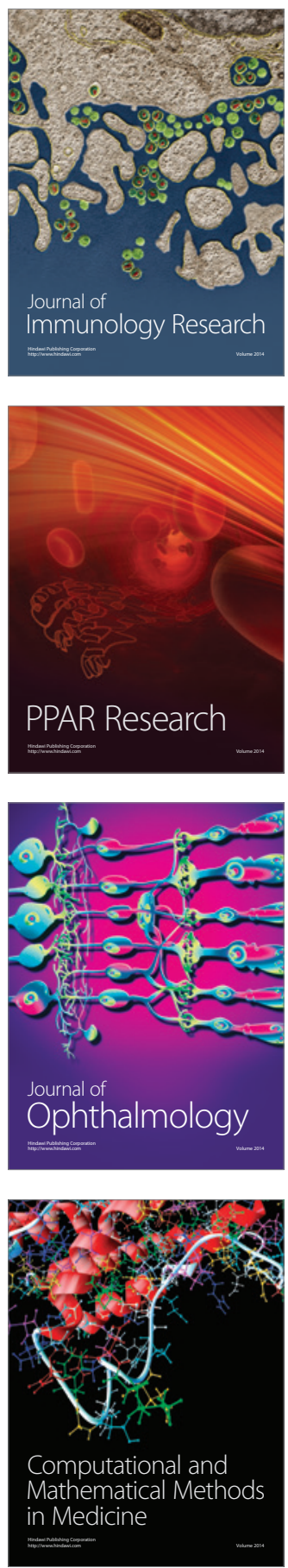

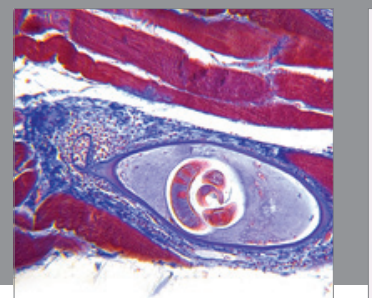

Gastroenterology

Research and Practice
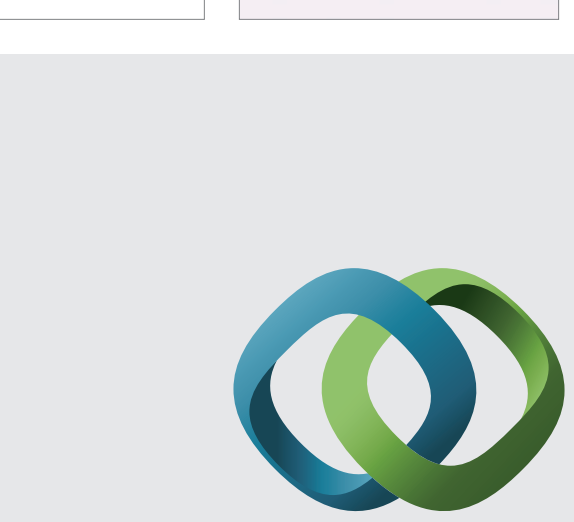

\section{Hindawi}

Submit your manuscripts at

http://www.hindawi.com
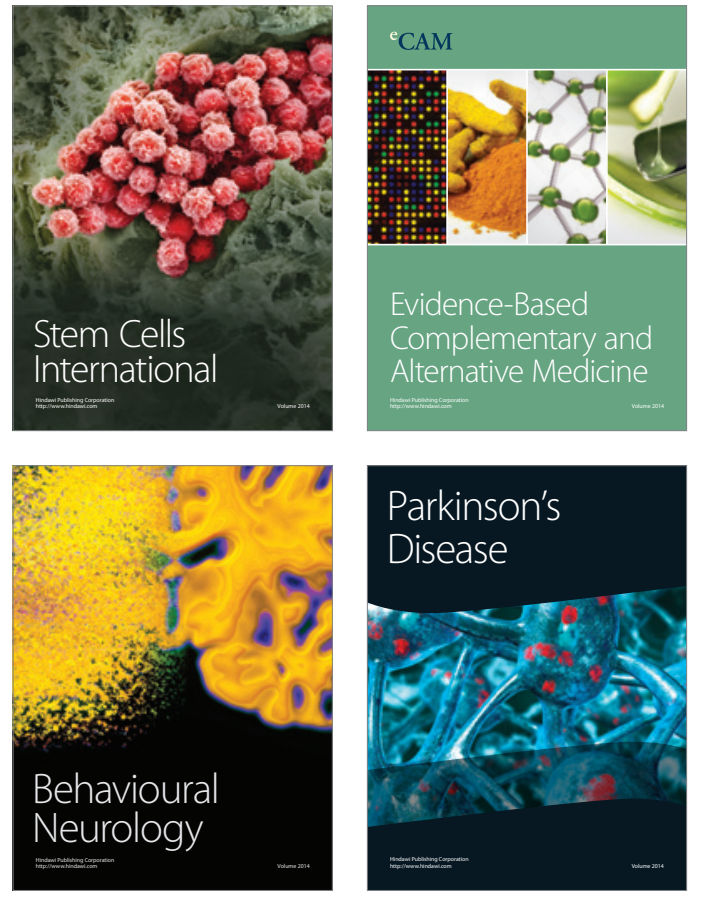
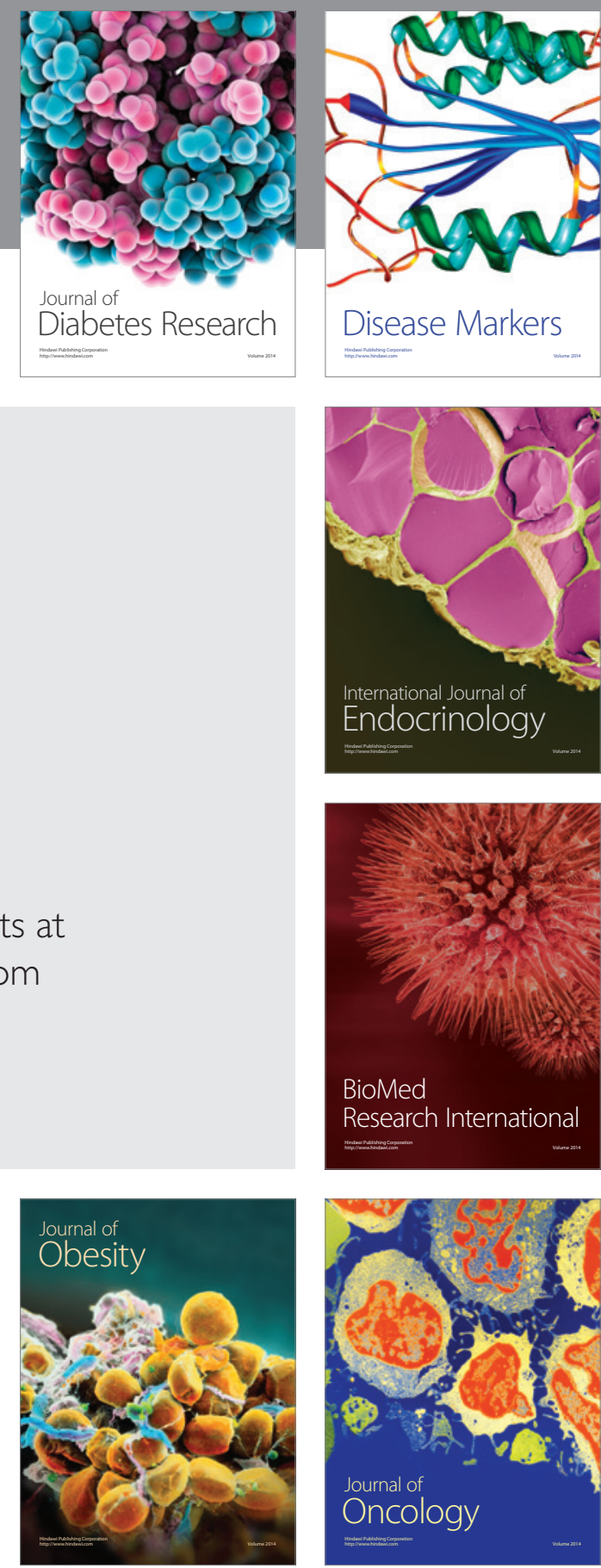

Disease Markers
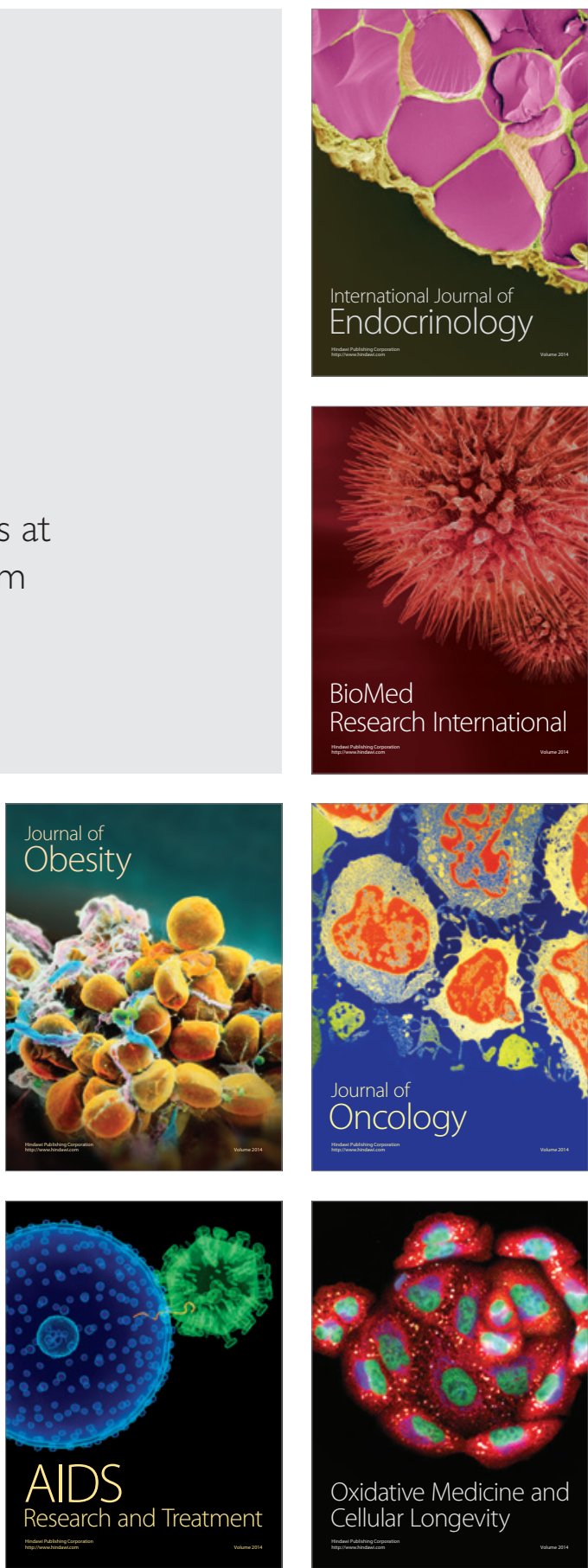